\title{
บUsisersily
}

\section{Between compassion and condemnation: a qualitative study of clergy views on suicide in Northern Ireland}

Leavey, G., Rondon-Sulbaran, J., \& McBride, P. (2011). Between compassion and condemnation: a qualitative study of clergy views on suicide in Northern Ireland. Mental Health, Religion \& Culture, 14(1), 65-74.

https://doi.org/10.1080/13674676.2010.502523

Link to publication record in Ulster University Research Portal

\section{Published in:}

Mental Health, Religion \& Culture

Publication Status:

Published (in print/issue): 01/01/2011

DOI:

10.1080/13674676.2010.502523

\section{Document Version}

Publisher's PDF, also known as Version of record

\section{General rights}

Copyright for the publications made accessible via Ulster University's Research Portal is retained by the author(s) and / or other copyright owners and it is a condition of accessing these publications that users recognise and abide by the legal requirements associated with these rights.

\section{Take down policy}

The Research Portal is Ulster University's institutional repository that provides access to Ulster's research outputs. Every effort has been made to ensure that content in the Research Portal does not infringe any person's rights, or applicable UK laws. If you discover content in the Research Portal that you believe breaches copyright or violates any law, please contact pure-support@ulster.ac.uk. 


\section{Between compassion and condemnation: a qualitative study of clergy views on suicide in Northern Ireland}

\section{Gerard Leavey , Janeet Rondon \& Peter McBride}

To cite this article: Gerard Leavey , Janeet Rondon \& Peter McBride (2011) Between compassion and condemnation: a qualitative study of clergy views on suicide in Northern Ireland, Mental Health, Religion \& Culture, 14:1, 65-74, DOI: 10.1080/13674676.2010.502523

To link to this article: http://dx.doi.org/10.1080/13674676.2010.502523

曲 Published online: 06 Feb 2011.

Submit your article to this journal

Џ Article views: 114

Q View related articles $\sqsubset$

Citing articles: 2 View citing articles 


\title{
Between compassion and condemnation: a qualitative study of clergy views on suicide in Northern Ireland
}

\author{
Gerard Leavey*, Janeet Rondon and Peter McBride \\ Compass - Centre for Mental Health Research, Northern Ireland Association for Mental \\ Health, Carecall, 80 University Street, Belfast BT7 $1 \mathrm{HE}, \mathrm{UK}$
}

(Received 16 April 2010; final version received 16 June 2010)

\begin{abstract}
The suicide rate in Northern Ireland, particularly among young men has grown rapidly in recent years. A relatively religious society, compared to other UK European regions, a needs assessment of clergy's pastoral response to mental illness and suicide was undertaken as part of the suicide prevention strategy. We carried out in-depth interviews with 37 clergy from a range of Christian denominations. While a compassionate response to suicide by clergy was commonly advocated, made permissible by an attribution to mental illness, there remain some misgivings about a "softer" theological stance towards suicide. This article describes clergy explanatory models of suicide and discusses the issue of cognitive dissonance on this subject.
\end{abstract}

Keywords: suicide; religion; pastoral care; mental illness; clergy; suicide prevention

\section{Introduction}

Religion offers material resources and a framework of meaning and action for living, suffering, dying and death across most cultures. Religious rituals, as the enactment of religious meanings, provide a means of affective processing, with or without active community engagement. It is usual, therefore, for clergy, of whatever faith community, to be called upon to officiate at or assist with such rituals.

Moreover, as part of their welfare and pastoral role, community-based clergy have significant contact with people who suffer from psychological and emotional health problems (Friedli, 1999, 2000; Wang, Berglund, \& Kessler, 2003); indeed many people experiencing what appears to be psychiatric illness are likely to seek out the help of clergy rather than psychiatric professionals (Mayers, Leavey, Vallianatou, \& Barker, 2007; Pargament, 1997). The work of clergy is often stressful and there is good evidence to suggest that clergy are highly susceptible to burnout (Lewis, Turton, \& Francis, 2007; Louden \& Francis, 2003). Other research in the United States indicates that clergy are reluctant to refer to psychiatric services (Wang et al., 2003) or have problems in discriminating between various psychopathologies (Domino, 1990).

Despite growing secularisation, Northern Ireland is still nominally a strongly religious country with high rates of church attendance. This has considerable significance in the

\footnotetext{
*Corresponding author. Email: gerardleavey@niamh.co.uk
} 
context of suicide and the ability or willingness of clergy to provide pastoral care to the bereaved. However, various studies in the United States have suggested clergy across all faith communities generally lack training, confidence and competence in dealing with such problems (Wang et al., 2003). Of importance to the current study, dealing with suicidal behaviour, self-harm and suicide may sit uneasily with many faith traditions, whereby the sanctity of life as God-given obliges a theological perspective of suicide as a sinful act, putting the person beyond God's forgiveness. Within such worldviews the act of suicide remains heavily stigmatised.

The Northern Ireland Suicide Prevention Strategy and Action Plan (2006) provided wide ranging targets for statutory agencies engaged in health promotion. The report allocated space to the needs of churches and other faith-based organisations in Northern Ireland, commonly regarded as maintaining an influential position in community life in Northern Ireland. However, the literature suggests that clergy may not be well prepared for pastoral care in matters related to mental health, emotional suffering and suicide (Leavey, 2008; Leavey, Loewenthal, \& King, 2007; Wang et al., 2003). Given the central role of clergy in many communities, a deeper understanding of the experiences and needs of clergy in the context of pre-suicide help-seeking and pastoral care in post-suicidal grief was deemed crucial to building partnerships with faith-based organisations.

\begin{abstract}
Aims
The overall aim of the study was to provide a better understanding of the needs of clergy in response to suicide and suicidal behaviour among a range of faith communities in Northern Ireland. The specific aims of the project were to examine the following: (a) Views and experiences of clergy with regard to suicide in their communities; (b) Barriers to pastoral care of people bereaved through suicide; and (c) Resources needed to enhance the pastoral response to suicide. In this article, ${ }^{1}$ we explore the problems of clergy in their attempt to navigate between community understandings of suicide and the strength of theological imperatives.
\end{abstract}

\title{
Method
}

It is generally difficult to anticipate clergy willingness to participate in projects of this kind. Previous research in the United Kingdom suggests the likelihood of a poor response rate. To deal with this difficulty we decided to approach recruitment through a two-pronged strategy. In the first stage, we identified a stratified random sample of community-based clergy. This was achieved by using lists provided by senior clergy involved with the steering committee who supplied names and addresses of clergy in the region. Clergy from minority faith groups not represented on the committee were added to the sample. They were identified through community organisations and then approached to take part. Generally, clergy were sent a brief letter to explain the project. We stressed our regard for confidentiality and anonymity. On an attached brief questionnaire, we asked clergy if they had ever had to deal with suicide among their congregation or had provided pastoral care to someone who expressed suicidal intent and/or would be interested in participating in a faith-based programme aimed at suicide prevention. We enclosed a stamped addressed envelope for reply. This was followed three weeks later with a follow-up letter and then a phone call. 


\section{Purposive sampling}

The potential participants for the qualitative study were selected from the responses to the postal survey. An integral aspect of the project was to describe and illuminate the experiences of clergy who have been confronted by suicide as part of their pastoral duties. Thus, we wanted to obtain rich phenomenological data that would provide an understanding of the specific experiences and worldviews of the participants (Denzin \& Lincoln, 1994). For this reason, from the completed survey data we purposively selected those clergy who reported contact with people bereaved through suicide.

\section{Topic-guide}

We developed a topic-guide that covered the following areas: personal views of mental health, suicide and suicidal behaviour; actual and ideal responses to suicide in the community; dealing with family members following suicide including burial and postburial pastoral care and support; community and congregational responses to suicide; faith-based organisation perspectives on supporting suicide prevention work such as the pastoral care of depression and other serious mental illness; an exploration of building relationships with statutory services; and shared or dissonant perspectives with other faith groups. In keeping with qualitative research values, we were open to pursue other issues as they emerged in the interviews. Importantly, we attempted a detailed exploration of related issues through actual clergy experiences of suicide within their own and other congregations. We undertook all interviews at a time and a place convenient to the participants. In the introductory letter and again at the interview, we stressed that the interviews were completely confidential and that they were free to terminate the interview at any time. We recorded the interviews using an audio digital recorder.

\section{Analysis}

Interviews were transcribed verbatim and analysed using Interpretative Phenomenological Analysis (Smith, Jarman, \& Osborn, 1999; Smith \& Osborn, 2003), an approach which attempts to understand lived experience and with how participants themselves comprehend their experiences; it is now widely used by researchers in health, clinical, and social psychology. The analysis followed the parameters and issues set out in the topic-guide. However, we were alert to new avenues of enquiry introduced by the clergy themselves. Thus, we anticipated that the qualitative analysis would assist in developing hypotheses on the personal and social responses to suicide, the role of clergy, community impact, training needs, and contact with services.

\section{Findings}

\section{Participants}

A sample of 37 Christian clergy participants represented the main denominations in Northern Ireland. This included: Presbyterian (10); Free Presbyterian (2); Baptist (1); Methodist (3); Catholic (8) and Church of Ireland (13). ${ }^{2}$ In line with qualitative methodologies, it is important to stress that the numbers of clergy interviewed within each of the denominations does not signify proportionate representation NI. We were not intending to make cross-denominational comparisons, although at times specifically 
denominational views may be apparent. Again on the issue of representativeness, only two participants were women. Although five female clergy responded to the questionnaire, of these, two requested not to be contacted; the three remaining were contacted and two of them gave interviews - Methodist and Church of Ireland ministers. The age range of the clergy interviewed was between 30 and 75 years; their years in ministry ranged from one to 51. The length of time the clergy have been in their current posts varied from a few months to 23 years.

\section{Causal explanations of suicide}

All clergy reported that the issue of suicide was of personal significance through neighbourly or community connections with individuals and families affected by suicide. Additionally, some clergy had been more personally affected by the suicide of someone close (a relative, friend or colleague). The instances of direct suicide experience among the clergy interviewed were varied - all participants had the experience of dealing at least with one suicide; exceptionally, one interviewee had experienced 20 cases. Some of their experiences were related to suicide clusters which have recently occurred in Northern Ireland. The causal explanations provided may be categorised as follows (a) sudden and inexplicable; (b) personal and family problems; (c) community problems; (d) modernity and secularism. However, as we outline these it is clear that these explanations are overlapping and that mental illness tends to underscore most explanatory models of suicide. In many cases, particularly among young people, the suicide was inexplicable to the clergy; an event lacking recognisable motivation. In other cases, suicide happens in the midst of apparent banal normality.

\section{Mental health problems}

Depression was the most frequently mentioned mental health problem referred to by the clergy; some with personal experience.

During that time of depression I did have myself, I went through a time, a particular evening actually, when I suppose the only way that you could describe it was that fear of death was gone and there was a kind of blackness descended over you and if I hadn't ... lifted the phone to speak to someone I mightn't be here today. (Presbyterian-ID18)

But many other descriptions were also given, of various states of being that don't fit any official diagnostic criteria, such as: mentally deranged, of unsound mind, having a chemical imbalance, not in their right mind, or having a nervous breakdown. The use of these terms appears to reflect the struggle for meaning. A consistent rationalisation suggested that in the absence of any obvious external problems and without any noticeable symptom or indicators of psychiatric disorder, the suicidal decision occurs instantaneously. Thus, as the following clergy suggests, while the suicidal action could not be described as resulting from mental illness, the mind has "crashed," metaphorically-speaking.

Does one go so far [as saying] that reason goes completely? Thinking about it, I would see it maybe as a brainstorm: somebody gets a stroke in the brain and there's no - well it's not rational anyway... It's not rational and reason is overcome by emotion. (Catholic-ID05) 


\section{Family and personal factors}

Family or personal problems were seen as precipitating factors in many suicides or attempts; generally a response to a personal crisis and deemed by the individual to be irremediable and thus, requiring escape.

So many unrealistic expectations and demands placed upon the family unit. When one or other partner can't measure up sometimes it's an easy way out... (Methodist-ID35)

Some people's lives are a real mess and they see no way out and the clouds come in, their thought processes go AWOL and the only way they see out... (Presbyterian-ID36)

\section{Community}

Suicides were seen by many as just a symptom of deeper societal issues. The interviewees spoke of an "awful instability" in children's lives, of social and family "brokenness," and widespread pain and suffering. Individual cases were seen as reflecting the overall mental health of the community:

The circumstances that...lead someone to take their own life seem...to be so individual and often hidden. I wonder how much can be achieved in terms of prevention other than by measures that address the general social and mental health of the community. (Church of Ireland-ID22)

The "Troubles" and its legacy were also seen as contributing to suicides in Northern Ireland, leading to an "unwillingness to come forward and speak" about problems such as violence, abuse, addictions and mental illness. And overall, due to 30 or 40 years of conflict, life itself was considered as devalued:

Just being able to go out there and take life, cheapened life. (Baptist-ID10)

\section{Modernity}

Alienation, especially among young people, was seen as a major factor. Despite young people having access to all sorts of communication (e-mail, mobiles, ordinary phones, text messages, etc.), they seem to be more alone than they ever were before, and lacking authentic human contact.

They're more in touch... but they're less in touch. (Baptist-ID10)

Thus, technology-aided relationships are much less valuable than real, face-to-face encounters; they lack intimacy, and lead to isolation. Especially for young people, in the world of real relationships - family, school, and church - they have nowhere to turn:

These were people who had nowhere to go...they actually mentally, emotionally and physically, intellectually, rationally and every sense had nowhere. They were totally in despair. (Catholic-ID02)

One interviewee mentioned a "very dark side to much of the entertainment" (Presbyterian-ID36) young people take in - from horror movies, to computer sites, to song lyrics and the Goth movement. The glorification of suicide by both the media and the larger culture also gets some blame, encouraging suicide to be seen as cool, and leading to "a big day out." And for males, the fact that talking is not seen as a macho thing was mentioned, as heart-to-heart talk with a trusted individual is seen as a way to avert suicide. 


\section{Secularism}

Relatedly, linked to notions of anomie (Durkheim, 1897), secularisation was seen as a problem. As one interviewee opined, "When spiritual values are at a low ebb, then society is at a low ebb" (Baptist-ID10). Most importantly, the guidance and structure that faith provides seems to be increasingly rejected. From the clergy perspective, society has lost its way, leading to a breakdown of the traditional family structure and values. A common perception among participants was that suicide itself became part of the cultural shift towards permissiveness and away from absolutes and imperatives:

The clear, clean cut thinking of...earlier generations has been replaced by a relaxed approach ...therefore in times of stress or trouble, suicide... can be in the thought pattern.

(Methodist-ID35)

Other institutions, including schools and the liberal media were seen as part of the problem by teaching young people to "radically question faith of any sort." Moreover, other clergy worried that evolution was being taught "as a fact," part of a general erosion which made suicide more acceptable, as "if we come from nothing, and we're going to nothing, then what's the point of life?" (Presbyterian-ID24). Moreover, young people, increasingly individualistic, have come under pressure to reject social norms and values; the internet plays a major part in this. There was concern about internet sites that actively encourage suicide and offer instructions on how to do it. Similarly, deviant peer groups (as described by some clergy) were also mentioned as a bad influence on young people's behaviour and thinking.

Interestingly, faith organisations themselves were not exempted from blame by clergy. Thus, while it was argued that religion was anchoring and sustaining, some clergy expressed a failure of the church in reaching out to people, retaining relevance.

\section{Theological views on suicide}

Suicide has been considered as anathema within most faith traditions. However, such views lacked the benefit of psychological or psychiatric insights into human suffering and behaviour gained over the past century. Anecdotal or media evidence on clergy response to suicide among community members suggests that more punitive attitudes to suicide have been replaced by more compassionate concern. However, a strong theological position on the sanctity of life, which remains constant among most faith groups, may add considerable complexity to the position of individual clergy as they attempt to offer condemnation on one hand and compassion on the other. Thus we wanted to examine the ways in which theological tenets about suicide might be accommodated by clergy.

Clergy across the range of denominations, universally and vigorously reiterated their belief that life is sacred. However, without exception, the participants stressed that suicide is predominantly the product of a mental illness - in which case, the previously assumed voluntary nature of suicide, a sin of despair, has been reframed as an involuntary act of a mentally ill individual, perhaps driven by stress beyond his or her "natural" or usual state by the confluence of various factors.

While some clergy suggested that other faith groups may hold punitive perceptions about suicide, the participants in the current study were clear that "hardline" views within the Christian tradition have shifted in the past 50 years and suicides are generally treated like any other death. Concepts and expressions such as compassion and forgiveness can be found throughout the transcripts while the notion of sin and shame are noticeably absent. They support (and are supported by) the fact that suicide has been decriminalised. 
Moreover, the traditions of not allowing the burial of a suicide on consecrated ground have been abolished. However, from these interviews it appears that, with one exception, there have not been any formal statements by any Christian denomination in which a softer view on suicidal behaviour has been outlined. Of course, several of the faith groups are non-hierarchical and as such lack central control or policy. Nevertheless, across all groups of whatever structure type, the approach to cases of suicide is generally left to the discretion of individual clergy. Significantly, clergy tend to distance themselves from a punitive view of suicide as sinful or use a sympathetic reconstruction of events which permits a reframing of the act as something other than suicide:

\footnotetext{
Because you see, many years ago, 40 years ago, you know the Church would have taken a very harsh line on anyone who committed suicide. They would have said they would not get into Heaven. And I think the Church was playing God there - they're not. They don't have the giving and the taking... I couldn't see of a God who would say to [anyone], 'You are banished forever.' (Catholic-ID03)

... over the last two years there has been a bill going through Synod [of the Church of Ireland] to encourage clergy in their ministry to suicides and suicide families and not to refuse burial of a suicide... I think the bill is to make it impossible for clergy to do that... I think the bill is just to formalise that suicides should be dealt with sensitively and the family should be ministered to carefully. (Church of Ireland-ID29)
}

[Within the Methodist Church] there would be a very compassionate understanding of suicide... So it's not the sort of approach which would say, because you commit suicide you're a terrible sinner and you'll go to hell, which is what you sometimes get from people. (Methodist-ID26)

Throughout the interviews, clergy stressed an explanatory model of mental illness in suicide, generally provoked by social and personal stressors and the use of drugs and alcohol. They noted that the stigma surrounding mental illness among faith communities has somewhat lessened. In tandem, a theological discourse of suicide has diminished; it has been replaced among clergy by a more psychological understanding of the phenomenon. Thus, an emphasis on psychiatric intervention is seen as more immediately appropriate than religious or spiritual remedy:

I think if we were being strictly theological, yes, it [suicide] would be regarded as a sin in that...theologically... God is the giver of life. But is suicide wrong?... if someone is terminally ill and in great pain causing ongoing great distress to loved ones who are dealing with them, I mean that certainly for me would come into it. And I don't think there is a blanket answer... I think there is a wealth of difference between suicide, if that's the word, in terminal illness and in following peer pressure... (Methodist-ID35)

\section{An alternative perspective is provided by the following minister}

I have to say, first of all, that suicide is sin. 'Thou shalt not kill.' And that has to be recognised. I think if that were more fully recognised, there might be fewer suicides. I know that suicide is no longer a crime. We're living in a secular society where people are saying to themselves, "Well if it's not a crime then it's all right.' I sometimes wonder if it were put very clearly to people, 'Here is something that is wrong.' Would they think twice about it? Or are we saying to people,'Look if you do this, we will have nothing but pity for you.' Are we encouraging people to - what's the word I'm looking for? - caress their own self-pity? I don't know. (Presbyterian -ID31)

\section{Discussion}

Suicide, compared to "normal" mortality, however young or unexpected, provokes incomprehension and anguish that are felt at the personal, social and political levels. 
A breakdown of the perceived "natural order" of things, it is often a multi-directional and polyvalent act, both meaningful and simultaneously meaningless for bereaved families, community and the wider society. Thus, while the intention of the suicide act may be regarded as an end to an individual's suffering it is usually the beginning of suffering for significant others, intended or not. And, in widening concentric circles of meaning, the act is an attack on society. For example, while bereaved families and shocked communities speak of incomprehension, beyond this their explanations for the act are balanced between a perceived individual vulnerability with macro problems of social injustice or anomie. For the more religiously conservative, the act may be regarded as a rejection of God and it is not hard to grasp the pivotal role of clergy as mediator in the community response.

To our knowledge, this is the first study to examine clergy attitudes towards suicide and how they reconcile theological injunctions against the act. There are limitations to this study, of course. First, the study was situated among clergy in Northern Ireland and it could be argued that some of the local factors may not be relevant to other places. Second, we were unable to obtain the views of the independent churches and sects. In these we might have uncovered less equivocal views on suicide. That said, there is little evidence to suggest that the issues grappled with here could be considered as peculiarly parochial or unusual. The narratives cover the social problems, the phenomenological experiences, the dilemmas and contradictions of religious service that might be envisaged in any Western, predominantly Judeo-Christian, setting.

Suicide ruptures assumptive worlds, often leaving a sense of shock and guilt with families and friends who struggle for meaning. In an arresting phrase, Douglas Davies (Davies, 2002, pp. 71-72) suggests that suicide is the opposite of a proper death so far as the idea of death transcendence is concerned, associated as it so often is, with despair, the sense of failure and weakness on the part of the individual who kills him or herself. Traditionally, the act of self-destruction, with the exception of politically or socially inspired actions as protest or in battle, is seldom viewed as noble or heroic. Indeed suicide is often considered as meaningless, a violation of the moral fabric, an egoistic, socially destructive act which cannot produce anything of value, except perhaps in some cases, a re-emergence of community cohesion through collective sorrow. Additionally, however, suicide also constructs a vicarious sense of failure, especially among family and, to some extent, among the wider community, inducing a sense of shame or guilt. In this way, through the act of suicide the suffering of the individual, the despair of failure, the guilt and the anger are projected into the community. Thus, in turn the bereaved feel considerable ambivalence to the suicide. Returning to Davies' comment on what might constitute a proper death, the suicide is deeply remembered but seldom commemorated.

In religious terms, suicide runs counter to religious values of acceptance or accommodation of suffering; indeed in the Catholic tradition particularly, suffering has long been regarded as offering divine connection through an affinity with the suffering Christ (Glucklich, 2001). However, suicide in many traditions is still regarded as sinful, a destructive act towards God's creation (and by implication, an attack on God), an abandonment or rejection of sacred love. The strictures against suicide have been established, most strongly in the Catholic world, through St Augustine and then Aquinas who described suicide as an act against self, neighbour and God; crucially, only God may decide life and death. Moreover, suicide precludes the individual from an act of confession and therefore the sins of the individual remain unexpunged. In Judaism, according to Kaplan and Schoenberg (1988), following a suicide, the soul is left without a resting place, 
unable to return to the body and unable to find peace in the soul worlds. Historically, in both the Catholic and Jewish traditions the dislocation of the soul was mirrored by a corporal dislocation; that is, the traditional burial rites and burial and sanctified earth was not accorded to those who killed themselves. However, in most traditions, exculpation is offered by faith communities when the individual is understood to be mentally ill.

However, it should be also recognised that many clergy reject the provision of mental health services as part of their role in ministry, and importantly, it is both inappropriate and unfair to assess their work on this kind of expertise. That said, many clergy understand the limits of their skills in counselling and welcome the opportunity to benefit from training in this field (Rupert \& Rogers, 1985). Nevertheless, in the context of disputed causation and ambivalent communal feelings, clergy occupy a difficult, often invidious, position. As the narratives in the current study illustrate, expectations are placed upon clergy by grieving families and communities and this adds perhaps to the considerable, unsolicited burden placed by clergy on themselves, to provide an answer or to give comfort; in some cases, to provide absolution.

However, albeit to a limited extent, clergy find themselves caught between theological and secular responses towards suicide; they remain trapped between their grief and sympathy for family and their religious abhorrence of the act, stuck between compassion and condemnation. Cognitive dissonance theory (Festinger, 1957) provides insights as to the reconciliation between contradictory beliefs and behaviour whereby people generally seek to reduce the discomfort this produces through an alteration of their cognitions, and behaviours, or alternatively, rationalising and accommodating these contradictions in some way. In the current study, many of the clergy adopt the defensive position that the individuals have killed themselves while "not themselves" and thus, their, mental illness permits forgiveness of the act. Of course, in many cases, they are unable to say for sure that the individuals were indeed mentally ill; they have to presume this to be so. Alternatively, they may state that they cannot presume to know the mental state of such individuals, only God can and therefore it is not the clergy's position to judge an event. They are obliged not to condemn.

And yet, many of these clergy are all too aware that a balance needs to be struck between private compassion - for the individual and the bereaved families and friends - and the public condemnation that the act of suicide requires; the need to be able to state that suicide is not acceptable. Throughout the interviews this dilemma is restated across all faith groups. The clergy adopt the position that religious antipathy towards suicide, the draconian religious denial to religious ritual burial and succour, has a significant deterrent effect. It follows therefore that any dilution of church condemnation of suicide may lead to an increase in the incidence. But, paradoxically of course, the clergy appear to be deeply anxious about secularisation, particularly among youth, increasingly disinclined towards religion. In other words, clergy battle against isolation and irrelevance while at the same time strongly insisting that religion is a major bulwark against the factors that generate suicide.

\section{Acknowledgements}

We are deeply indebted to the many clergy who assisted in this research. They generously disclosed their difficult and moving experiences and offered important insights to their generally unacknowledged, compassionate work. We are also very grateful to the members of Journey Towards Healing programme who made this sensitive work possible. 


\section{References}

Davies, D. (2002). Death, ritual, belief. New York: Continuum.

Denzin, N.K., \& Lincoln, Y.S. (1994). Handbook of qualitative research. Thousand Oaks, CA: Sage.

Department of Health Social Services \& Public Safety. (2006). Northern Ireland Suicide Prevention Strategy and Action Plan 2006-2011. Belfast: DHSSPS.

Domino, G. (1990). Clergy's knowledge of psychopathology. Journal of Psychology and Theology, 18(1), 32-39.

Durkheim, E. (1897). Suicide. New York, NY: The Free Press reprint 1997.

Festinger, L. (1957). A theory of cognitive dissonance. Stanford, CA: Stanford University Press.

Friedli, L. (1999). Promoting mental health: The role of faith communities - Jewish and Christian communities. London: Health Education Authority.

Friedli, L. (2000). A matter of faith: Religion and mental health. International Journal of Health Promotion, 2(2), 7-13.

Glucklich, A. (2001). Sacred pain: Hurting the body for the sake of the soul. Oxford: Oxford University Press.

Leavey, G. (2008). UK Clergy and people in mental distress: Community and patterns of pastoral care. Transcultural Psychiatry, 45, 79-104.

Leavey, G., Loewenthal, K., \& King, M. (2007). Challenges to sanctuary: The clergy as a resource for mental health care in the community. Social Science and Medicine, 65, 548-559.

Lewis, C.A., Turton, D.W., \& Francis, L. (2007). Clergy work-related psychological health, stress and burnout: An introduction to this special issue of Mental Health, Religion \& Culture. Mental Health, Religion \& Culture, 10(1), 1-8.

Louden, S.H., \& Francis, L.J. (2003). The Naked Parish Priest: What priests really think they're doing. 1st ed. London: Continuum.

Mayers, C., Leavey, G., Vallianatou, C., \& Barker, C. (2007). How clients with religious or spiritual beliefs experience psychological help-seeking and therapy: A qualitative study. Clinical Psychology and Psychotherapy, 314(4), 317-327.

Pargament, K.I. (1997). The psychology of religion and coping: Theory, research, practice (1st ed.). New York: The Guilford Press.

Rupert, P.P., \& Rogers, M.L. (1985). Needs assessment in the development of a clergy consultation service. Journal of Psychology and Theology, 13(1), 50-60.

Smith, J.A., Jarman, M., \& Osborn, M. (1999). Doing Interpretative phenomenological analysis. In M. Murray \& K. Chamberlain (Eds.), Qualitative health psychology: Theories and methods (pp. 218-240). London: Sage.

Smith, J.A., \& Osborn, M. (2003). Interpretative phenomenological analysis. In J. A. Smith (Ed.), Qualitative psychology: A practical guide to research methods (pp. 51-80). London: Sage.

Wang, P.S., Berglund, P.A., \& Kessler, R.C. (2003). Patterns and correlates of contacting clergy for mental disorders in the United States. Health Services Research, 38(2), 647-673. 